\title{
EL SAINETE DEL ÚLTIMO TERCIO DEL SIGLO XIX, CULMINACIÓN DE UN GÉNERO DRAMÁTICO EN EL TEATRO ESPAÑOL
}

M." Pilar Espín Templado

UNED

\section{Del antiguo entremés o paso al SAINETE MODERNo}

La etimología de la palabra «sainete» nos indica que procede del término provenzal «sain», que a su vez deriva del latín «sagina», que quiere decir «grosura de un animal». Según la Real Academia Española, «sainete» equivale a "pedacito de gordura», de tuétano o sesos que los halconeros o cazadores de volatería daban al halcón o a otro pájaro de cetrería cuando lo cobraban». También en sentido figurado equivale a «bocadito delicado y gustoso al paladar» ${ }^{1}$. Así pues el vocablo "sainete», de su significado primitivo como término de cetrería y/o de cocina (equivalente a algo apetitoso), según consta también en el Tesoro de la Lengua Castellana de 1606 de Sebastián Covarrubias ${ }^{2}$, pasa, por extensión, a significar algo deleitoso, ameno o divertido; lógicamente al terreno del teatro se extiende la palabra «sainete» en lo que connotaba de diversión y especialmente cuando iba condimentada con bailes.

La primera aplicación de la palabra «sainete» al teatro, parece ser

\footnotetext{
1 Diccionario de la Lengua Española. Real Academia Española. Vigésima edición. Madrid, Espasa Calpe, 1984. Tomo II, p. 1.210. Acepciones 2." y 6." respectivamente.

2 Tesoro de la Lengua Castellana o Española de Sebastián de Covarrubias. Madrid, Turner, 1979, p. 9.212, 2." acepción: SAYN, «La grosura de cualquier animal, del nombre latino sagina, saginae; y porque los caçadores de bolateria o halconeros, quando cobran el pájaro le dan o los tuetanitos del ave, o los sesos, o otra cosita regalada (lo cual llaman sainete), vino a estenderse este nombre a los bocaditos de gusto, quales suele traer el cocinero al señor, para que le mande dar de bever de su frascon.
} 
que se debe a Ricardo del Turia, en su Apologético por las comedias españolas (Norte de la Poesía Española, Valencia 1616), y lo da como «intermedio estimulante del gusto del público que pedía en las comedias el tono de la música, no sólo alegre y joli, pero corrido y bullicioso, y aun avivado con sainetes de bailes y danzas que mezclan en ellas» ${ }^{3}$. En adelante proliferan las alusiones del vocablo «sainete» a toda «pieza intermedia de cualquier género que fuese, siendo por lo tanto errónea la difundida creencia de que las piezas dramáticas, que en el siglo XVII llevaban el nombre de "sainetes", eran cosa distinta de los "entremeses", sino que en dicho siglo, y todavía a inicios del siglo XVIII, "sainete" era nombre genérico que unas veces se aplicaba al entremés, más comúnmente al baile y a la jácara, mojiganga y otros fines de fiesta" ${ }^{4}$. Los mismos autores propiciaron el confusionismo entre los varios géneros, hasta el punto que en 1726, el Diccionario de Autoridades definió la palabra «sainete» como sinónimo de «baile»: «Baile. Se dice también el intermedio que se hace en las comedias españolas entre la segunda y la tercera jornada, cantado y bailado, y por eso llamado así, que por otro nombre se llama "sainete" "s.

Pero antes de situarnos en el momento histórico en el que el sainete, ocupando el lugar de los «bailes» ${ }^{6}$, sustituye y renueva al antiguo entremés, veamos cómo las denominaciones «paso», «entremés» y «sainete» se suceden cronológicamente para designar las mismas piezas de teatro jocosas.

Aunque la palabra «entremés» no se aplicó a las «representaciones breves de carácter dramático» hasta el siglo $\mathrm{XVI}^{7}$, sin embargo éstas

${ }^{3}$ Emilio Cotarelo y Mori, Colección de Entremeses, Loas, Bailes, Jácaras y Mojigangas desde fines del siglo XVI a mediados del siglo XVIII. Nueva Biblioteca de Autores Españoles, tomo XVII. Madrid, 1911, p. CXXXIX.

4 ldem. p. CXXXVIII y sig.

5 Diccionario de Autoridades. Madrid, R.A.E., 1726. Edición facsímil Gredos, 1969. p. 531, tomo I.

También entre los términos baile y entremés, hubo confusión, a pesar de las notables diferencias formales entre ambos géneros ya que los editores barajaban los rótulos en tiempos de L. Quiñones de Benavente, esto es en la primera mitad del siglo XVII. El término sainete, que después llegó a ser genérico, se usaba en esta época sin gran precisión. aunque parece más bien referirse al entremés cantado, esto es al baile. H. E. Bergman, Luis Quiñones de Benavente y sus entremeses. Madrid, Castalia, 1965, p. 29 y nota).

6 El baile dramático no sólo consistía en un baile tripudio, sino que conllevaba asimismo recitación, música y canto, entre todo lo cual se desarrollaba una acción por medio de unos personajes. Como género literario, el baile nace cuando se independiza del entremés, y pasa a ocupar uno de los intermedios de la comedia, pudiendo situarse su nacimiento en los últimos años del siglo XVI y comienzos del XVII, y muriendo definitivamente en el primer tercio del siglo XVIII con la aparición de los sainetes costumbristas. (Gaspar Merino Quijano: Los bailes dramáticos en el siglo XVII. Madrid, Universidad Complutense, 1981, pp. 735 y 736, vol. I).

7 J. E. Gillet, «An Easter-Play by Juan de Pedraza», Revue Hispanique LXXXI, 1933 , p.533 y nota. Gillet documenta por primera vez la palabra kentremés» en el sentido 
existieron desde los inicios de nuestro teatro, ya que como «pasos» o "entremeses" medievales «en potencia» podrían ser consideradas las piezas de Juan del Enzina (Auto del Repelón, dos Representaciones hechas en la noche del Carnal), o la farsa de Lucas Fernández de Dos pastores, Antona y un soldado, o igualmente algunas farsas de Gil Vicente, sin olvidar los intermedios o pasajes burlescos que Diego Sánchez de Badajoz intercala en obras principales ${ }^{8}$.

Ya en el siglo XVI nos encontramos con la denominación explícita de "pasos» equivalente a la de «entremeses» en las obras de Lope de Rueda y de su discípulo Juan de Timoneda ${ }^{9}$. La producción entremesil de Cervantes prestigiará este peculiar género dramático que será cultivado durante los siglos XVI y XVII por varios y famosos autores, tales como: Alonso Jerónimo de Salas Barbadillo, Alonso de Castillo Solórzano, Antonio Hurtado de Mendoza, Francisco de Quevedo, Luis Quiñones de Benavente, Luis Vélez de Guevara, Luis de Belmonte Bermúdez, Román Montero, Francisco Navarrete y Ribera, el cual «queriendo apartarse de lo usual, comenzo por dar a su colección el título de «Flor de Sainetes (Madrid, 1640), si bien en el encabezado de cada pieza, le llama entremés o baile» 10 . También Pedro Calderón de la Barca fue un excelente entremesista, como es sabido, y asimismo Jeronimo del Cáncer y Velasco, Francisco Bernardo de Quirós, y Agustín Moreto cultivaron el género. Tras la producción de este último, se inicia la decadencia del entremés, y en los dos últimos decenios del siglo XVII y primeros diez años del siguiente, destacaron como principales entremesistas Francisco de Castro, Antonio de Zamora (autor de mu-

de «pieza intermedia” en 1549. A. Bonilla y San Martín, en Las Bacantes o del origen del teatro. Discurso leído ante la Real Academia Española, Madrid, 1921, cita la palabra kentremésm por primera vez en Castilla en el Doctrinal de Caballeros de D. Alonso de Cartagena, Libro III, cuya 1." edición es de 1487, en el sentido de diversión o pasatiempo. Véase también Cotarelo, $O b$. cit. pp. LIV-LX.

${ }^{8}$ La opinión de que existen unos antecedentes del entremés anteriores a los pasos de Lope de Rueda, la expresan más o menos detenidamente: Cotarelo, Ob, cit. pp. LX y LXI. Jack William Shaffer. The Early Entremés in Spain: The Rise of a dramatic Form. Philadelphia, 1923, p. 39. A. Bonilla y San Martín, Las Bacantes o del origen del teatro. Madrid, Real Academia Española, 1921, p. 130. H. E. Bergman, Luis Quiñones de Benavente y sus entremeses. Madrid, Castalia, 1965, p. 27. Eugenio Asensio, Itinerario del entremés... Madrid, 2." edic. revisada. Gredos, 1971, p. 35 (1." edic., 1965). Humberto López Morales: Tradición y creación en los origenes del teatro castellano. Madrid, Ed. Alcalá, 1968, p. 201-214 y 224-228.

"La posible diferencia genérica entre las obras denominadas «pasos» o «entremeses», ha sido definitivamente zanjada tras el planteamiento progresivo del problema por: E. Cotarelo y Mori, Ob. cit., p. LIX. A. Bonilla y San Martín: Ob. cit., p.129, nota 2. F. Lázaro Cárreter, «El Arte Nuevo (vs. 64-73) y el término entremés». Anuario de Letras $V$, pp. 77-92, 1965. F. González Olle: Introducción a Pasos de Lope de Rueda. Madrid, Cátedra, 1984, pp. 46-50.

io E. Cotarelo y Mori, Ob. cit., p. CXL. 
chas y excelentes comedias) y Cañizares, aunque este último sólo escribió nueve entremeses. Del desconocido Juan de Agramont y Toledo, partió la idea de escribir cuatro o cinco entremeses, más extensos, al estilo de lo que luego lograría con todo acierto don Ramón de la Cruz. Agramont los tituló "sainetes», y lo mismo hicieron otros autores de su tiempo. De esta manera, cuando en 1757, empezó don Ramón de la Cruz a componer los suyos, el nombre estaba ya plenamente aceptado en el teatro.

Así pues, el nombre de «sainete» fue siendo cada vez más empleado como designador de las mismas piezas breves y jocosas, antes denominadas pasos o entremeses, que acompañaban la comedia, llegando a predominar y ocupando el lugar de los bailes, entre la segunda y la tercera jornada. Esta situación perduró casi todo el siglo XVIII, hasta que en 1778 se suprimieron los entremeses antiguos, desapareciendo simultáneamente el nombre de «entremés». Las causas de que los entremeses antiguos desapareciesen del primer intermedio (lugar que ocupaban desde principios del siglo XVIII), fueron fundamentalmente dos: por un lado, lo bajo e indecoroso en que habían caído que "aun al pueblo bajo disgustaban»; por otro lado, se daba la circunstancia de que, al no hacerse ya bailes en el segundo intermedio, sino que su lugar había sido ocupado por el «sainete», como hemos dicho, el cual era un segundo entremés, resultaba reiterativa esta repetición de dos piezas iguales ${ }^{11}$.

En palabras de J. Subirá que corroboran las de Cotarelo: «Al desaparecer los bailes, los sainetes ocuparon el puesto de ellos entre la segunda y la tercera jornadas, sin que entonces se distinguieran en nada de los entremeses, salvo en lo eventual y accesorio, pues cuando esas piezas menores se colocaban entre el primero y el segundo acto, recibían el nombre de «entremés», y cuando se las intercalaba entre los actos segundo y tercero, se las denominaba «sainetes». Esto es tan firme como constante ${ }^{12}$.

Nos encontramos así que la última etapa de revitalización del género «sainete» en el siglo XVIII, corresponde a la producción del gran don Ramón de la Cruz, cuya obra abarca desde 1762 hasta 1792. Otro sainetista contemporáneo suyo, aunque más joven y no de su misma categoría literaria, fue el gaditano Juan Ignacio González del Castillo (1763-1800).

Una última fase, en este breve recorrido histórico del género dramático «sainete» nos queda por revisar antes de llegar a la generación de saineteros del último tercio del siglo XIX; se trata del período cronoló-

"Idem, pp. CXLIV a CLVII.

12 José Subirá, "Géneros musicales de tradición popular y otros géneros novísimos» en $H .{ }^{\circ}$ General de las Literaturas Hispánicas. Barcelona, 1950, tomo IV, $1 .{ }^{4}$ parte. 
gico comprendido entre 1800 y 1860 . El teatro en vísperas del Romanticismo se vio invadido por un auténtico aluvión de traducciones. Entre éstas ocuparon un lugar preferente las comedias en un acto y los «vaudevilles», de importación francesa (igual que la mayoría de las comedias traducidas); con los «vaudevilles» se pretendía sustituir, por anticuados, los viejos sainetes, sin embargo, a pesar de dicha competencia, el sainete siguió en la cumbre de la popularidad como «fin de fiesta». Además, esta forma dramática abundó mucho más que cualquier otra (como prueba el testimonio de las carteleras teatrales madrileñas que llenan este espacio cronológico) ${ }^{13}$, y conservó, en esencia, la estructura que había alcanzado en el siglo XVIII con Cruz y seguidores; en consecuencia, el sainete no sufre cambio alguno durante la primera mitad del siglo XIX, lo que explica que se siguieran representando todavía muchas de las piezas antiguas, especialmente las más famosas de Ramón de la Cruz y de González del Castillo ${ }^{14}$.

Hasta aquí, hemos podido observar que el género dramático menor llamado paso, entremés o sainete, según la época histórica y el autor, desempeñaba un papel de complementariedad dentro del conjunto que constituía la representación teatral completa. Ésta, en los siglos de oro, como es bien sabido, estaba integrada por una sucesión de varias piezas menores que antecedían, se intercalabam o cerraban la comedia principal.

El sentido que estas piezas teatrales tenían de «complemento» o "accesorio» de la comedia principal, no debe engañarnos, respecto a su importante protagonismo dentro del conjunto del espectáculo teatral, en lo que a éxito de público se refiere. Tanto en los siglos de oro, como en el siglo XVIII, fueron importante aliciente y estímulo para la asistencia del público a una determinada función en caso de que fuera de su agrado, o para su inasistencia, en caso contrario. Tanto era así, que el éxito de cartel de una comedia podía aumentar o disminuir según estas piezas menores fueran o no del gusto del «respetable». Si hemos de creer al protagonista de Luis Quiñones de Benavente (Madrid, 1645), «el autor que tenía una mala comedia, con ponerle dos entremeses de este ingenio le daba muletas para que no cayese, y el que tenía una buena, le ponía alas para que remontase» ${ }^{15}$. En este sentido, René Andioc demuestra cómo las tonadillas y sainetes que completaban las funciones del siglo XVIII «tenían tantos aficionados como las comedias $y$, en efecto, no pocas veces se observa una subida repentina de las

${ }^{13}$ Cartelera teatral madrileña I (1830-1839) y II (1840-1849), Madrid, Cuadernos bibliográficos, C.S.I.C., 1961 y 1963.

If John Kenneth Leslie, Ventura de la Vega and the Spanish Theatre 1820-1865. Princenton, 1940, p. 33.

15 Eugenio Asensio, Ob. cit., p. 15. 
recaudaciones después de la mera sustitución del sainete que completa el programa»... «Se comprende, pues, por qué Iriarte, como muchos neoclásicos, quiere suprimir o bien dejar para después de concluida la comedia estos elementos de diversión a los que parte del público concede más importancia que al desenlace de la obra principal» ${ }^{16}$.

\section{El SAINETE ENTRE 1870 Y 1910}

Finalmente llegamos al último tercio del siglo XIX, época durante la cual el sainete resurge de nuevo gracias a los autores del Teatro por Horas ${ }^{17}$. Se tratará, claro está, de otro tipo de sainete, diferente del de los siglos de oro y del dieciochesco, como también este último difería de aquél; sin embargo, muchos de sus elementos pervivirán de manera que podría hablarse de una constante evolución del género sainete. Fundamentalmente, la primera gran diferencia que podemos destacar del moderno sainete fin de siglo es su pérdida de complementariedad, de elemento accesorio de la función principal. Esta vez, el sainete va a evolucionar dando de sí más de lo que cabría esperar de una pieza tildada de «menor»: además de conservar su carácter de pieza breve, popular y jocosa, pasa, nada menos que de obrita complementaria de la función principal, a ser ésta misma, la obra única y exclusiva del espectáculo. El sainete, tras siglos de existencia dramática «simbiótica», alcanza su propia independencia, logrando entidad y fundamento en sí mismo, sin necesidad de apoyarse en otras comedias. Esta culminación del género se debió, en primer lugar, a su propia evolución histórica, pero también se vio favorecida por una circunstancia concomitante y primordial: el nacimiento del Teatro por Horas que encumbraba las piezas breves, hasta el momento complementarias, erigiéndolas en funciones principales con entidad en sí mismas.

Enunciaremos las características esenciales del sainete decimonónico, tratando de establecer en qué consistió dicho género entre 1870 y

${ }^{16}$ René Andioc. Teatro y Sociedad en el Madrid del siglo xvIII. Valencia, Fundación J. March/Castalia, 1976, pp. 33 y 34.

${ }_{17}$ El Teatro por Horas fue un sistema de organización teatral, surgido a raíz de la Revolución de 1868 . consistente en ofrecer al público cuatro obras diversas, de un acto cada una, durante cuatro horas consecutivas, con entrada independiente en cada caso. Las obras podian ser líricas o no, y fueron englobadas en la común denominación de Género Chico. Los libretistas del Género Chico pertenecieron a dos generaciones: la de 1868 y la de 1898 , ya que el Teatro por Horas pervivió durante cuarenta años. Para una mayor documentación de este teátro véase la publicación de mi tesis doctoral: El Teatro por Horas en Madrid: 1820-1910, de próxima aparición. 
1910 , con las peculiaridades que esta época le otorga, y las reminiscencias y herencias que aún conserva de la tradición ${ }^{18}$.

El sainete moderno continúa siendo un género dramático breve ${ }^{19}$, cuya extensión oscila entre 20 y 40 páginas escritas en libretos de 20 a $25 \mathrm{~cm}$., pues la representación escénica de este género y de todos los del Teatro por Horas - de ahí precisamente esta denominación- no podía exceder la duración de una hora, dadas las características intrínsecas de este tipo de teatro.

Su estructura escénica se basaba fundamentalmente en un cuadro o en varios (de dos a cuatro normalmente, a veces cinco como máximo) con la consiguiente ausencia o presencia de una a cuatro mutaciones, siempre dentro del acto único.

La música podía hacer o no acto de presencia según el gusto del autor. Cuando el sainete cuenta con elemento lírico, éste nunca ahoga ni anula las escenas dialogadas, sino que alterna con ellas, no siendo nunca mayor el número de escenas musicadas orquestalmente o lo que es más usual, con acompañamiento del canto, que el número de escenas sin música. El baile también aparece con mucha frecuencia, por lo menos en alguna de las escenas musicales de los sainetes líricos, como otro elemento escénico e integrado y consecuente con la acción que se desarrolla en ese momento.

El número de personajes que participa en cada sainete suele ser muy numeroso, oscilando frecuentemente entre 20 y 30 , muy rara vez es inferior a 10.

18 Para ello nos basamos en el análisis pormenorizado de 122 sainetes en un acto escrito entre 1867 y 1916 de un elenco de diez escritores escogidos de entre las dos generaciones de autores por horas: Miguel Ramos Carrión, Ricardo de la Vega, Javier de Burgos, Fernando Manzano. Tomás Luceño, Emilio Sánchez Pastor, Vital Aza, Carlos Fndez.-Shaw, José López Silva y Celso Lucio. Muchos de los sainetes analizados fueron escritos en colaboración, por lo que debemos mencionar también a los siguientes coautores: M. Echegaray, Carlos Arniches, Jackson Veyán, R. Asensio Más, Julio Pellicer, Ricardo Monasterio, Fiacro Iraizoz, Félix Limendoux, Antonio Ramos Martín, Toro Luna, Mario Muzas, Pina Domínguez y Calixto Navarro.

${ }_{19}$ No somos ajenos a la problemática que se extiende tras esta «simplificación genérica», claramente puesta de manifiesto en la ponencia de $\mathbf{M}$. A. Garrido Gallardo: «Notas sobre el sainete como género literarion en El Teatro menor en España a partir del siglo xVI (Actas del Coloquio celebrado en Madrid, 20-22 de mayo de 1982). Madrid, Anejos de la Revista de Segismundo, 5, 1983). En primer lugar, hay sainetes de más de un acto (como el mismo Garrido Gallardo objeta al analizar la problemática del género), incluso entre nuestros mismos autores. Nosotros, sin embargo, al movernos dentro del marco teatral que supuso el Teatro por Horas, nos atenemos en consecuencia a las piezas del acto único, cuya duración de representación no excedía de una hora. Tampoco nos planteamos, pues sería salirnos fuera de los límites de nuestra investigación, la problemática de la definición genérica del sainete clásico o dieciochesco. Desde luego, partimos del supuesto de considerar al sainete como "género histórico», cuyos rasgos constitutivos básicos entre 1870 y 1910 y dentro del marco del Teatro por Horas, nos proponemos delimitar. 
Finalmente los sainetes fueron escritos en prosa o en verso, predominando más estos últimos, y sobre todo, si tenemos en cuenta que los cantables de los sainetes en prosa siempre eran en verso, vemos que la versificación aparece en una mayoría de sainetes. También un grupo de ellos alternaban la prosa y el verso, cantables aparte. Es importante repetir que el sainete en el Teatro por Horas constituía la única representación en sí misma, perdiendo el carácter de complementariedad de la función principal que siempre había caracterizado al género sainete a lo largo de su historia.

\section{CONTINUACIÓN DE LA TRADICIÓN LITERARIA POR PARTE DE LOS SAINETES DEL ÚLTIMO TERCIO DEL SIGLO XIX}

El primero de nuestros sainetes contemporáneos (que tengamos noticia), dentro de la producción de los autores por horas seleccionados, fue estrenado en el teatro Lope de Rueda, el 31 de enero de 1870 . Su título era Cuadros al fresco y su autor Tomás Luceño.

Es revelador, sin embargo, que, todavía antes de este estreno, Luceño escribiera el sainete ¿Cuántas, calentitas, cuántas? subtitulado "continuación de Las Castañeras picadas de don Ramón de la Cruz», que la muerte de Julián Romea, el 10 de agosto de 1868, quien hacía de primer actor, impidió su estreno, que no se efectuaría hasta $1910^{20}$.

Este dato nos indica la voluntad, por parte de la nueva generación de saineteros, consciente y deliberada, de continuar lo que era el sainete dentro de la tradición literaria del género.

Esta determinación de seguir la línea del sainete tradicional fue detectada por la crítica de la época y posterior. Ya el crítico catalán J. Ixart afirmaba: «... el sainete no desmiente su origen. Restaurado hace algunos años, en plena evolución realista y naturalista, pareció la exacta adopción de la explícita fórmula de don Ramón de la Cruz, el primer sainetero del siglo pasado... Los saineteros de hoy no han hecho más que imitar aquellas obras...» 21 .

Posteriormente, un importante crítico de nuestros días, Torrente Ballester, afirmará: «En cuanto al teatro contemporáneo no moderno, es decir, al que, por su materia dramática, por su intención y sus procedimientos, se relaciona con el teatro popular del siglo XIX... desde el principio camina por tierra explorada y trillada... Sabido es que la tra-

20 Tomás Luceño, «Mi teatrillo» en «El Teatro». Madrid, 6 y 13 de febrero de 1910.

21 José Ixart, El arte escénico en España. Barcelona. Imprenta de La Vanguardia, 1896. Vol. II, pp. 106 y sig. 
dición dramática nacional, agotada en sus manifestaciones eminentes, perdura, sin embargo, en las populares, y que desde el entremés del siglo XVI al sainete contemporáneo puede establecerse una línea de continuidad ininterrumpida» 22 .

Es pues claro, que nos encontramos ante un género dramático tan antiguo como nuestro teatro, y cuyo carácter distintivo, como el de todo género literario, «se va relevando paulatinamente en su historia, a lo largo de la cual, mediante variadas transmutaciones, va buscando su identidad y posibilidades» ${ }^{23}$. Esto es exactamente lo que le sucede al género entremesil desde sus balbuceos con los «pasos» de Lope de Rueda, los «entremeses», desde Cervantes pasando por Quiñones de Benavente hasta Quevedo, y los «sainetes» de un Ramón de la Cruz a un Ricardo de la Vega o un Tomás Luceño. Esto nos confirma que un género literario vive y se desarrolla y que la causa que en su día originó dicho género puede muy bien desaparecer, y sus características modificarse experimentando una evolución o incluso una brusca revolución, y, a pesar de ello, el género sigue viviendo «genéticamente», o sea, «en virtud de una orientación natural de la costumbre que lleva las nuevas obras a agregarse a los géneros ya existentes" ${ }^{24}$. En el caso del sainete sucede que la máxima revolución por él experimentada se produce en el último tercio del siglo XIX y primera década del siguiente siglo, con la desaparición de la causa que lo originó como género: el ser intermedio de la comedia, pasando a ser él mismo la única "comedia».

\section{REALISMO Y COSTUMBRISMO EN EL SAINETE DECIMONÓNICO}

Se han señalado el "valor documental» y el "españolismo» como elementos constitutivos del sainete. Valor documental, en el sentido de que el mismo desarrollo del sainete muestra la evolución de la sociedad que en él se refleja; en segundo lugar se le considera algo «tan intrínseco como esencial, por cuanto ha brotado del pueblo español, que en él, se ve gozosa y hasta dolorosamente representado» 25 .

${ }^{22}$ Gonzalo Torrente Ballester, Introducción al Teatro Español Contemporáneo. Madrid, Guadarrama, 1957, pp. 25 y 32.

${ }^{23}$ E. Asensio, $O b$. cit., p. 16.

24 Boris Tomachevski, Teoría de la Literatura. Madrid, Akal, 1982. «Los géneros literarios", p. 212.

${ }_{25}$ "Vicente Ramos, “Naturaleza y evolución del sainete» en Vida y Teatro de Carlos Arniches. Madrid, Alfaguara, 1966, capit. VIII, p. 66. y J. Cejador y Frauca, Historia de la Lengua y Literatura castellanas. Madrid, Tipología de la Revista de Archivos, 1915-22. 3. ed., 1932. Reproducción fascímil: Gredos, 1972, tomo IX, p. 10. 
Hay que tener en cuenta, que tanto el valor documental, como el "españolismo», de darse efectivamente en el sainete como el citado crítico afirma, emanarían de un realismo en el que se inspiraría el género (lo cual veremos posteriormente), al que José Nogales define como «un trozo de vida hábil y certeramente enfocado, sorprendido en su espontánea actividad y trasladado a la escena como se traslada un tiesto de flores» ${ }^{26}$.

También para el ya mencionado crítico catalán J. Ixart, el sainete representó una fiel y artística transcripción de la vida popular en sus aspectos más vulgares; lo cual hace que este género, en su opinión, sobresalga y se diferencie de otros que se dieron en el Teatro por Horas, como la revista, el juguete cómico, la parodia, la zarzuela..., etc ${ }^{27}$.

Para otro historiador del Género Chico, Deleyto y Piñuela, el sainete en la época que nos ocupa consiste en «observación de tipos y escenas, tomados de la vida real y presentados en su aspecto jocoso» ${ }^{28}$.

Hemos visto cómo la mayoría de los críticos que opinaron sobre el sainete lo calificaron de género realista, atribución que corroboramos, pero que creemos necesario matizar; en efecto las reiteradas acotaciones que enmarcan el sainete en la «época actual» junto con los espacios dramáticos escogidos para los cuadros escénicos, reiteran de una manera inequívoca la intención de transportar verazmente a los escenarios ambientes interiores o exteriores de Madrid, de Andalucía o de cualquier pueblo de España. En el caso del sainete madrileño, que es el predominante en la producción analizada, los autores se esfuerzan, y lo consiguen, en trasplantar a la escena, las calles y la vida de Madrid. Todos los lugares más característicos de la capital: la Plaza Mayor, el arco de Cuchilleros, la calle de Toledo, la pradera del Canal, las orillas del Manzanares..., etc., las gentes que pululan de la más variopinta condición, verduleras, sietemesinos, marqueses, cesantes, chulos, toreros, porteras..., etc., y las múltiples referencias a los usos y costumbres de la época, locales públicos de moda: cafés, teatros, restaurantes, paseos, hasta los periódicos de más tirada, desfilan por el sainete, recreando y dando color a una época que de otro modo se nos hubiera escapado en su «intrahistorian, en su vivir más elemental y sencillo. El sainete fin de siglo es pues plenamente realista en cuanto a espacios y personajes, los cuales se muestran en el teatro hablando según la clase social a la que pertenezcan y según su localización dentro de España.

Ahora bien, si el realismo atañe a espacios y personajes, la acción de los sainetes, su temática, ya adolece de más convenciones literarias:

26 José Nogales, "Madrid Cómico", 22, septiembre, 1900).

27 José Ixart, $O b$. cit., vol. II, pp. 106 y sig.

2* José Deleito y Piñuela, Origen y Apogeo del Género Chico. Madrid, Revista de Occidente, 1949. p. 323. 
el final feliz que culmina siempre en boda de los jóvenes, la misma trama artificiosa del enredo amoroso; no obstante, esto, que mermaría el grado de realismo, no influye en exceso pues la fábula del sainete queda prácticamente en segundo plano, ocupando el primero el ambiente costumbrista y el desfile de los personajes-tipo, o la crítica o sátira de ciertas lacras sociales o defectos humanos.

Sin embargo hay que ser consciente de que toda realidad, en su tratamiento artístico, por muy fidedignamente que quiera ser tratada, sufre una cierta e inevitable «estilización» o si se quiere «literaturización», que por otra parte influye a su vez en el público, es decir, en la vida real. Este influjo mutuo entre la gente de la calle llevada a la escena y encarnada en los personajes teatrales, y el público, la gente real, que se ve a sí misma caricaturizada en las tablas fue un hecho palpable en la tremenda popularidad del género ${ }^{29}$.

También Antonio Valencia hace hincapié en esto al afirmar «lo que el Género Chico excedió fue en mostrar una visión sainetesca del pueblo madrileño, en que no se sabe si la naturaleza imitaba al arte o la realidad a lo teatral...» ${ }^{30}$.

Esta mixtificación entre realidad y teatro se muestra de una manera todavía más diáfana en el lenguaje que algunos autores ponen en boca de los personajes de los sainetes; el caso de Arniches es el más típico por la originalidad y fuerza cómica conseguidas a través de sus hallazgos léxicos. Arniches «trata de hacer hablar a los personajes como si fueran gentes populares, pero para ello se requiere subentender previamente un determinado módulo de popularismo muy lejano de la realidad» ${ }^{31}$.

Bien es verdad que el de Arniches es un caso extremo de «estilización» léxica frente a saineteros mucho más respetuosos con el lenguaje popular real, como es el caso de Ricardo de la Vega, Tomás Luceño o José López Silva; sin embargo, vaya el lenguaje como ejemplo de uno de los muchos aspectos que al aplicar el término realista a nuestros sainetes, debemos tener presentes para no incurrir en falsas simplificaciones.

El término «costumbrismo», entendido en su sentido más amplio como descripción o pintura de costumbres que muestran la vida del hombre y de la sociedad coetáneas del autor, se encuentra obviamente en los antecedentes literarios más remotos del género que nos ocupa (paso, entremés o sainete de los siglos XVI-XVII y XVIII), y también, in-

29 Julio Cejador y Frauca, Ob. cit., tomo IX, p. 16.

30 Antonio Valencia, El Género Chico (Antología de rextos completos). Madrid, Taurus, 1962, p. 15.

31 Ricardo Senabre, «Creación y deformación en la lengua de Arniches». Segismundo, II, 1968, p. 296. 
dudablemente, en el sainete moderno finisecular, objeto de nuestro estudio.

Este costumbrismo que entronca con lo genuino del pueblo en una época determinada: su continuidad, hábitat, sus bailes, fiestas, vestidos típicos y hablas, jergas y dialectos, y que como costumbrismo realista hacía ver las diferencias de las distintas regiones españolas (sainete andaluz frente a sainete madrileño), enlaza evidentemente con el folklore, y desde este punto de vista se le atribuyó desde siempre un carácter nacional, un nacionalismo que se oponía a lo extranjerizante.

De hecho en 1897, fecha en que se celebra por primera vez en Apolo «la fiesta del sainete» en pleno auge del género sainete, se hace un esfuerzo por parte de organizaciones como la Asociación de la Prensa de Madrid, por enlazar el sainete en la tradición de un teatro popular nacional; para ello se celebra anualmente una función por entero dedicada al «españolísimo género que se llama sainete... algo castizo, algo genuinamente nacional» ${ }^{32}$. A partir de este momento los términos «español» y «nacional» serán aplicados continuamente por la crítica al referirse al «sainete». Y ciertamente no se puede decir que dichos adjetivos estuvieran impropiamente aplicados, ya que la fuente de la inspiración sainetera había sido la vida popular, "no en lo que ésta tenía de común y semejante en toda España, sino en lo que tenía de diferente»... "El sainete del siglo XIX había cultivado el hecho diferencial y en el conjunto de las regiones favorecidas, la vida del pueblo madrileño se había incorporado al sainete en su pintoresquismo..." ${ }^{33}$; en efecto, el sainete era un género regionalista, casi un género folklórico que contrastaba con el afán extranjerizante que venía invadiendo la escena española desde muy atrás en el siglo XIX a base de multitud de traducciones de obras, en su mayoría francesas o italianas.

Es decir, por un lado, el costumbrismo realista resaltaba el «hecho diferencial» entre las diversas regiones españolas, entroncando con el folklore, y por otro lado, siguiendo con la anterior cita de Torrente Ballester «...dentro del cuadro general de la vida madrileña existían también hechos diferenciales y que el sainete los cultivaba». Este tratamiento especial de un sector de la vida social madrileña ha sido destacado como un posible rasgo temático configurador del género histórico claramente delimitable que es el sainete ${ }^{34}$.

32 Jose Francos Rodríguez: El Teatro en España 1908. Madrid, Imprenta de Nuevo Mundo, s. a., pp. 39-46: "La fiesta del sainete", y V. Ruiz Albéniz (Chispero): Ob. cit., p. 267.

${ }^{33}$ Gonzalo Torrentes Ballester, Teatro Español Contemporáneo. Madrid, Guadarrama, 1957, p. 32 (Subrayado del autor). Más adelante, el crítico matiza dos tipos de hechos diferenciales: el regional, y dentro de uno de ellos, concretamente del madrileñismo, el de un grupo social determinado, el pueblo.

34 M. A. Garrido Gallardo, «Notas sobre el sainete como género literario» en El tea- 
Para corroborar si efectivamente se da en el sainete finisecular la presencia de un grupo social que destaque como «hecho diferencial», revisaremos los espacios donde se desarrolla la acción, así como la procedencia social de la mayoría de los personajes que pueblan los sainetes, contrastándolos con la realidad social del Madrid finisecular, apoyándonos en estudios sociales de la época.

Comencemos por los espacios escénicos más frecuentes en el sainete madrileño, el patio de las llamadas en la época «casas de vecindad», y las calles de los «barrios bajos», además de los lugares de recreo a las afueras de Madrid, a la orilla del Manzanares.

Los términos «barrios bajos» o «barrios del extrarradio madrileño» sirven con frecuencia para ubicar la acción de los sainetes que transcurren en la calle: «Una calle de los barrios bajos de Madrid» El amo de la calle, C. Arniches-J. López Silva 1910); «... Tienda de comestibles en un barrio extremo de Madrid..." (Ultramarinos, T. Luceño, 1886); "Gran portal en una casa de vecinos de los barrios bajos...» (Las Mujeres, J. de Burgos, 1896); "Una plazoleta de los barrios bajos...» (Viva Córdoba, C. Fndez.-Shaw R. Asensio Más, 1902); «Una callejuela del barrio de Bellas Vistas. Las miserables casuchas que la forman, albergue de traperos y de gente de parecida ralea, son todas viejas y medio derruidas, estando separadas entre sí por tapias y corralillos... Un paisaje, en fin, que da la nota triste de los áridos suburbios madrileños». (El maldito dinero, C. Arniches-C. Fndez. Shaw, 1906); en el mismo sainete, la acotación del cuadro tercero dice: «Interior de la casa de los Carroñas, tugurio pequeño de aspecto miserable, lóbrego y sucio...».

$\mathrm{Si}$ investigamos acerca de la vivienda y los barrios populares madrileños a finales del pasado siglo, la clasificación abarcaría, empezando por abajo, por las más humildes, las chozas del extrarradio madrileño y acabaría en las «casas de corredor» o "de vecindad», hábitat que aparece como el más digno dentro de la clase social más baja. Los barrios extremos madrileños citados en las anteriores acotaciones, en la realidad eran fundamentalmente: La Elipa, Los Tejares del Sixto, La Casa Blanca, La Casa del Cabrero, El barrio de las Injurias y Perico el Gordo. Todas las casas de estas barriadas eran de planta baja y de condiciones higiénicas deleznables: faltas de luz solar y de espacio suficiente para albergar a la gente pobre que cobijaban. Parecidas a las barriadas citadas pero con más pretensiones en sus viviendas, por tener éstas dos o tres pisos y responder los barrios a algún trazado, eran los de la Prosperidad, La Guindalera y los Cuatro Caminos, formados por estrechas calles y defectuosas construcciones ${ }^{35}$.

tro menor en España a partir del siglo Xvi. Anejos de la Revista «Segismundo», C.S.I.C., Madrid, 1983, pp. 18-20.

35 Carmen del Moral, La sociedad madrileña fin de siglo y Baroja. Madrid. Turner, 
De estas casas más pretenciosas también tenemos mención en los sainetes, donde son calificadas de «modernas»: «Una calle. Frente al público, ocupando casi todo el escenario, la fachada de una casa grande, moderna, de tres pisos...» "Una calle del barrio de la Latina. Dos casas ocupando el escenario. La de la izquierda pobre y muy antigua... la de la derecha no es tan antigua y tiene tres pisos..." (La verbena de la Paloma, R. de la Vega, 1894); «Dos casas grandes modernas, que forman una calle en el centro, no muy ancha, que va hasta el foro..." (Aquí va a haber algo gordo, R. de la Vega, 1897).

Ya en el interior de Madrid, la vivienda popular más prototípica era la casa de corredor o de vecindad, muchas de ellas situadas en las rondas o en sus cercanías, aunque la mayoría estaban diseminadas por casi todos los distritos de la capital. Representaban unas 438 casas con un total de 52.521 habitantes, correspondiendo a cada casa un promedio de 1.200 personas, siendo por tanto el hacinamiento la característica más destacada de estas viviendas "colectivas» habitadas por la clase obrera $o$ indigente.

El aspecto de estas casas de corredor, según las descripciones de Hauser y Chicote, coincide plenamente con los decorados escénicos que, tan repetidamente, hemos visto aparecer en los sainetes madrileños, como espacios donde transcurría la acción. «Dichas casas se componian en general de un número bastante grande de habitaciones o cuartos, distribuidos en una o dos piezas con poca luz. La mayor parte de ellas estaban provistas de patio donde había una fuente con agua para todos los vecinos, existiendo otras que ni siquiera tenían fuente y había que ir por agua a una fuente pública próxima...» «... Estas casas se hallaban en las más deplorables condiciones higiénicas. Todas carecían de aseo y limpieza, unas tenían una sola fuente para toda la casa y un solo retrete para cada piso; muchas carecían de agua y hasta de luz, y no eran aptas para ser habitadas por seres humanos» ${ }^{36}$. Recuérdese el escenario de La canción de la Lola, de $\mathrm{R}$. de la Vega, sainete estrenado en 1880, por citar uno de los primeros: «El teatro representa un patio de vecindad: corredor a una altura conveniente. Puertas arriba y abajo, que dan a las habitaciones de los vecinos. Fuente en el centro. Portón que da a la calle...»

Para concluir con la revisión de los espacios más frecuentados en el sainete madrileño, mencionaremos por último los lugares de esparci-

1947. pp. 88 y sig. La autora se documenta fundamentalmente en la obra de César Chicote: La vivienda insalubre en Madrid, Madrid, Imprenta Municipal, 1914 pp. 48 y 88, y en la obra que citamos a continuación.

${ }_{36}$ Philliph Hauser, Madrid bajo el punto de vista médico-social... Madrid, Establecimiento tipográfico *Sucesores de Rivadeneyra», 1902, Edición preparada por Carmen del Moral. Madrid, Editora Nacional, 1979, pp. 322-324, vol. I. 
miento popular o de trabajo de la clase obrera, situados en los márgenes del Manzanares, a las afueras de Madrid. Nos referimos concretamente a los merenderos de la Bombilla o a los lavaderos, sitios frecuentados ambos por la clase baja. También otros espacios exteriores de diversión popular escogidos por el sainete, son las verbenas o ferias, fiestas de carácter netamente popular, algunas de ellas arraigadas a una antiquísima tradición, como la feria de San Isidro ${ }^{37}$.

Respecto a los personajes que pueblan los sainetes, y que habitaban estas casas de vecindad, pertenecían, en la realidad social de la época, «a la clase obrera o indigente, que más podríamos calificar de subproletariado que de proletariado propiamente dicho" ${ }^{38}$. Se componía este vecindario, en su mayoría, de la clase jornalera, de empleados cesantes, de vendedores ambulantes, de barrenderos y de traperos (es decir, de todos los personajes que protagonizan los sainetes), siendo los barrios bajos o populares donde estaban la mayor parte de las casas de corredor y donde también se aglomeraba la mayoría de la clase obrera ${ }^{39}$.

Comprobamos, pues, que tanto en lo que se refiere a los espacios como a los personajes, el sector social de la población que destaca como protagonista del sainete, es sin duda, la clase social más baja. La aparición esporádica de señoritos burgueses o aristrócratas acentúa el contraste de clase, pero nunca supone una presencia mayoritaria, ni protagonista, dentro del numeroso acopio de personajes populares que llenan el escenario del sainete.

En conclusión, podemos resumir que la vida de la clase inferior de la población es la que cobra relieve, distinguiéndose en el género sainete; la clase obrera, trabajadora, la que vive según los estudios de la época en condiciones de un subproletariado, muy lejos del grado de higiene y confort mínimos deseables. Desde este punto de vista, el sainete es fielmente realista y costumbrista, en cuanto a presentación de tipos y ambientes. Por el contrario, no nos parece veraz ni realista el grado de felicidad que rezuman dichos personajes, y que adorna el costumbrismo descrito.

Normalmente la realidad iba reñida con la felicidad en el teatro «serio» finisecular (recordemos los dramones de Echegaray); el sainete parece querer demostrar lo contrario: la felicidad es posible, pese a la sórdida realidad en la que vive la clase más menesterosa de la sociedad. Hay en ello, sin duda, una idealización de ese «modus vivendi» de la

${ }^{37}$ Ver el libro de J. Deleito y Piñuela: También se divierte el pueblo (Recuerdos de hace tres siglo). Romerias, Verbenas, Bailes, Carnaval... Madrid, Espasa Calpe, 1954 (2." edic.)

W Carmen del Moral, $O b$. cit., pp. 92 y 93.

${ }^{39}$ Ob. cit., p. 326. 
clase social que hasta el momento había estado proscrita de los escenarios.

Hemos llegado al punto, pues, de mostrar que el costumbrismo realista, entendiendo dicho término en su sentido más amplio, nos ha detectado en el sainete finisecular dos elementos distintivos y propios del género: su regionalismo o folklorismo por un lado, es decir, la diferenciación de las diversas costumbres de dos pueblos de España: del madrileño y del andaluz, y por otro lado, su «clasismo», si denominamos así al hecho de que una clase social - la inferior - sea la protagonista, en términos generales del sainete.

\section{EL COSTUMBRISMO ROMÁNTICO Y SU INFLUJO EN EL SAINETE FINISECULAR}

Centrémonos ahora en el Costumbrismo Romántico o Moderno, es decir, en el movimiento literario cuyo desarrollo tuvo lugar entre 1830 y 1850 fundamentalmente; aunque vinculado a la narrativa, en nuestra opinión influirá de una manera bastante decisiva en la preparación del ambiente y gustos literarios necesarios para el triunfo definitivo y la inmensa popularidad que el moderno sainete alcanzó.

El artículo o cuadro de costumbres propio del costumbrismo romántico ofrece una personalidad concreta y definida: «Es siempre una composición breve, en prosa o en verso y que tiene por finalidad la pintura filosófica, festiva o satírica de las costumbres populares, o en un sentido más amplio la pintura moral de la sociedad. Sus temas concretos son la descripción de tipos, escenas, lugares o instituciones de la vida social contemporánea con escasa o ninguna trama argumental. En cuanto a la tendencia de su contenido, presenta un carácter variable: ya es satírico o didáctico con propósito de reforma de la moral o la sociedad; ya pintoresquista, humorístico o realista descriptivo, sin preocupación ulterior del puro entretenimiento" 40 .

La definición de Ucelay engloba, subrayadas, las palabras de Mesonero (Panorama matritense, Madrid, 1862, p. XVII), y toda ella, como vemos, podría aplicarse sin ningún empacho al sainete del último cuarto del siglo XIX.

Dos géneros distintos, el artículo de costumbres y el sainete fin de siglo, con cuarenta años de mediación aproximadamente entre el nacimiento de uno y otro, se asemejan sorprendentemente, no sólo en in-

* Margarita Ucelay Da Cal. Los españoles pintados por si mismos, 1843-1844. Estll. dio de un género costumbrisı. México, 1951. pp. 21 y sig. 
tención y contenidos sino también en la forma, a pesar de pertenecer uno de ellos al campo de la narrativa y el otro al dramático.

Aunque se haya apuntado que «el artículo de costumbres en su fondo y en su forma representa una fusión feliz del ensayo y del cuento ${ }^{41}$; sin embargo también ha sido sugerido por la crítica que «sucedáneo de la novela (el cuadro de costumbres) aspira a ser una narración dramática ${ }^{42}$. Mención ésta que, a nuestro entender, nos parece bastante clave que haya sido subrayada por Fernández Montesinos, cuando a lo largo de todo su ensayo pretende demostrar cuán próximo se encuentra el cuadro de costumbres del cuento. La evidente proximidad del cuadro costumbrista con el género sainete en sus contenidos, intención y forma dramática en esbozo, la vuelve a sugerir Montesinos cuando afirma: "La realidad observada será la que la vida actual nos ofrece en torno; el espíritu es el de antaño, manifestado en el giro y la palabra castizos... Muchos de nuestros costumbristas han insistido en esto, en que venían a continuar la historia de España... y recuerdan a la picaresca, a Cadarso - Cartas Marruecas- y más oportunos son aún los recuerdos de don Ramón de la Cruz, tan próximo a este novísimo costumbrismo y verdadero precursor del gusto por la manoleria cochambrosa y lenguaraz. Cruz humorista antiheroico, como Mesonero humorista antirromático» ${ }^{43}$. Y, más adelante, al relacionar el periodismo con el costumbrismo, en cuanto que ambos contribuyeron al «descubrimiento de la realidad circunstante», Montesinos alude, muy directamente, al precedente que el costumbrismo de Mesoneros va a significar para la posterior tarea de nuestros saineteros: «El empleo de dialectos provinciales... va a encontrar propugnadores en estos costumbristas atentos al detalle... limitados aún a la simple transcripción de las formas fonéticas más aparentes, otros vendrán después que aquilaten el valor de la lengua hablada, bien o mal, en diversas regiones españolas y le den un papel en la obra de arte. Mesonero, una vez más se ha contentado con señalar una pista. Curioso es, de todos modos, que los leves dejos de lenguaje hablado de que para sus caracterizaciones se urde procedan de hablas regionales y que no se haya parado mientes en la popular de Madrid. Aún está lejos el día en que los nuevos saineteros inventen -en los dos sentidos de la palabra-el madrileñismo ${ }^{44}$.

Es decir, F. Montesinos ve a Cruz como uno de los precursores del

"I Idem. p. 17.

42 José Fndez. Montesinos, Costumbrismo y Novela. Ensayo sobre el redescubrimiento de la realidad española. Madrid, Castalia, 1980, 4. " edic. p. 14. (El subrayado es mío.)

${ }^{4.3}$ Idem. pp. 14 y 15 (subrayado mío). La influencia del sainete de Ramón de la Cruz en el desarrollo de la literatura de costumbres de principios del siglo XIX ha sido también apuntada por C. Tarr. "Romanticismo in Spain" (P.M.L.A. LV, March, 1940, number I, p. 44 n. 12) y por P. Le Gentil: Le poete Manuel Bretón de los Herreros..., pp. 236-237.

44 Idem. pp. 70 y 71 (subrayado mío). 
Costumbrismo Moderno, y a éste a su vez como un antecedente clarísimo de la labor de nuestros modernos saineteros. La interinfluencia y ósmosis entre los géneros son evidentes pues, aunque de hecho el Costumbrismo moderno se inicia con la fundación de la revista literaria Cartas Españolas en 1831 por José María Carnerero, en realidad su boga rebasa con mucho la época romántica. Para ello no tenemos más que fijarnos en la serie de repetidas imitaciones de que fue objeto la obra Los españoles pintados por sí mismos, dos volúmenes publicados en Madrid en 1843 y 1844 por el editor Ignacio Boix. Este libro, muy de actualidad en la época, fue obra colectiva en la que colaboraron literatos profesionales, eruditos, políticos o profesionales liberales. En cada volumen se describian 49 tipos, profesionales, psicológicos o ideológicos, estudiando su apariencia física, su vida, costumbres..., etc., a la manera de la moda literaria que imperaba en la época, llamada «Fisiología».

Muchos de estos tipos serán los que pueblen nuestros posteriores sainetes: los tipos populares procedentes de determinadas regiones y que tradicionalmente desempeñaban ciertos oficios en Madrid como «el aguador», «el sereno», «el cochero», «la nodriza»; los tipos urbanos de la clase media, «el empleado», "el cesante», o los del sector o estamento político, «el diputado», «el senador» y en general todos los tipos populares, menestrales o profesiones humildes, presentadas de forma humoristica, «tipos cómicos cuya comicidad está basada en su tosquedad, su miseria y su ignorancia» 45 .

La afición por esta "tipología» en la que se pretendía caracterizar la personalidad nacional, se extendió a través de las publicaciones «pintorescas" ${ }^{46}$, que como hemos dicho se multiplicaron en un deseo de imitación de Los Españoles... Así en 1871-72 reinando Amadeo de Saboya y simultáneamente al incipiente renacer del moderno sainete, "renace el gusto por este género y se publican otras tres colecciones: Las españolas pintadas por los españoles (2 vols., Madrid, 1871-72), Los españoles de Ogaño (sic) (2 vols., Madrid, 1872) y Las mujeres españolas, portuguesas y americanas ( 3 vols., Madrid, $1872-73$ y 76). Todavía en 1885 , y ahora sí que nos encontramos en pleno auge del sainete en el Teatro por Horas, se publican dos colecciones, Los hombres Españoles, Americanos y Lusitanos pintados por sí mismos y Las mujeres Españolas, Americanas y Lusitanas pintadas por si mismas, libros que según M. Ucelay uaun siendo los más distantes cronológicamente de Los españoles... están más cerca del carácter de éstos» ${ }^{47}$.

45 M. Ucelay Da Cal, Ob. cit., p. 124.

46 El adjetivo "pintorescon significaba entonces que la revista llevaba ilustraciones.

47 M. Ucelay Da Cal, Ob. cit., «Obras derivadas», pp. 181-210. 
Toda esta proliferación de obras tardías «tipológicas» y «pintoresquistas» nos hace patente cómo el gusto literario nacido con el costumbrismo por los años 30 no había muerto en las décadas 70 y 80 en las que el interés por los tipos, representativos de una idiosincracia nacional, perdura y cobra nueva vida en otro género literario, el sainete dramático; en este sentido el sainete, inversamente a lo sucedido en el siglo anterior, que había servido de inspiración a los costumbristas de principios del siglo XIX, se nutre ahora de ellos y sigue claramente las huellas no sólo de estas obras colectivas sino las del más genuino cultivador del artículo costumbrista madrileño: Mesonero Romanos (18031882).

Frente a un Estébanez Calderón más irreal en la presentación de una Andalucía algo anacrónica, o frente a Larra cuyo costumbrismo adquiere distinto tono debido a su profundidad y mordiente crítica, Mesonero Romanos se nos aparece como el más castizo retratista del ambiente madrileño en un estilo que recuerda, salvando las distancias de épocas y géneros, la labor de Ramón de la Cruz, y desde luego anticipa y abre caminos en la posterior labor de los saineteros.

La misma definición que de sus cuadros hace Mesonero, refleja to cerca que situaba a éstos de una breve pieza dramática tipo sainete: «Propúseme desarrollar mi plan por medio de ligeros bosquejos o cuadros de caballete en que ayudados de una acción dramática y sencilla, caracteres verosímiles y variados, y diálogo animado y castizo, procurara reunir en lo posible el interés y las condiciones principales de la novela y del drama» ${ }^{48}$.

Montesinos se lamenta de que no entren en los dominios del cuento los escritos de Mesonero que él mismo ha calificado de «narraciones dramáticas» y afirma que «... el que Mesonero llame siempre cuadro, tal vez estudio, frecuentemente articulo, los suyos de costumbres nada dice de su esencia» ${ }^{49}$. Desde luego que el nombre por sí solo no hace al género pero lo que sí se evidencia, cuando Mesonero describe sus artículos explicando que ha querido unir en ellos lo narrativo y lo dramático, cuando los titula «cuadros» dotados de «acción dramática sencilla», es que la idea de una breve pieza escénica rondaba su narración. De hecho el mismo Montesinos confiesa que en Día de toros (1836), Mesonero «ha estado a punto de pasar a la novela todo un mundo de realidad y se ha quedado en una imitación de don Ramón de la Cruz» ${ }^{50}$.

Parece pues razonable afirmar que nuestros saineteros del último tercio del siglo pasado continuaron, en cierto modo, la tradición cos-

4* Ramón Mesonero Romanos: Panorama Matritense, p. 12, y Memorias..., p. 88 en Obras Completas, Madrid, Renacimiento. 1925.

${ }^{44}$ J.F. Montesinos, $O b$. cit., p. 60.

s) Idem, p. 65. 
tumbrista de «tipos» y "escenas» persistente a través del arrollador éxito de Los españoles pintados por sí mismos y de las creaciones de Mesonero en su Panorama Matritense, aunque el protagonismo de las clases medias que retrató el Curioso Parlante fuera ampliado al del cuarto estado preferido por los saineteros.

Mesonero contribuyó al movimiento literario del costumbrismo romántico con la famosa revista por él fundada «El Seminario Pintoresco Español» cuya finalidad era «generalizar la afición a la lectura y el conocimiento de las cosas del País, así en su belleza natural como en sus monumentos artísticos, ya en la vida y hechos de sus hijos ilustres, como en la historia y tradiciones de sus localidades, usos y costumbres del pueblo...m. Por otro lado, a pesar de que la intención de Mesonero, según confiesa en sus Memorias, era la de retratar todas las clases sociales, el resultado fue que «la inmensa mayoría de las Escenas registradas por el Curioso Parlante se circunscriben, en realidad, a un círculo social determinado: la clase media, en sus distintos estratos. El bajo pueblo, por lo general, sólo se evoca como telón de fondo. Salvo alguna excepción: La capa vieja y el baile del candil, El barbero de Ma. drid, El paseo de Juana... o el delicioso esbozo de novela trazado en dos relatos, El recién venido, y España en Madrid" "51.

Mesonero, sin embargo, evoluciona en esta postergación de retratar al pueblo, y desde un explícito desprecio hacia el mismo en el Manual de la Villa y Corte de 1831, hasta la última edición de éste en 1854, en donde elogia a la manolería madrileña. De hecho, en sus apuntes de 1854 -repoducidos luego en tipos y caracteres- «Mesonero registra la transición de los personajes de $\mathrm{R}$. de la Cruz a los del Género Chico" resultando curioso que los adelantos de refinamiento, progresos y cosmopolitismo que Mesonero señala como logrados a mediados de siglo por el pueblo madrileño, desde nuestra actual perspectiva del siglo $X X$ han pasado a constituir precisamente los rasgos casticistas típicos de los personajes zarzueleros de Mesonero:

«... Trocando para ir a los toros el antiguo y estrepitoso calesín por el ómnibus comunista, las seguidillas por la polka, la bandurria y el pandero por la orquesta militar o el organillo alemán..." sz.

Mesonero Romanos, constituye así un eslabón entre el costumbrismo romántico desde una perspectiva burguesa y el costumbrismo fin

s1 Carlos Seco Serrano, Sociedad, Literatura y politica en la España del siglo $x i x$, Madrid. Guadiana. 1973. «Mesonero Romanos: La pleamar burguesa». pp. 137-275 y pp. 238 y ss.

$\leq 2$ Idem, p. 245. 
de siglo patente en el sainete del Teatro por Horas, cuyos autores, procedentes de una clase pequeño-burguesa venida a menos, darán un paso más en la descripción de la tipología, sumando a las clases medias, la clase social inferior que protagonizará, en este caso, las pequeñas obras dramáticas que nos ocupan. De este modo, es posible advertir, teniendo presentes obviamente las diferencias cronológicas y de géneros-literarios, unas ciertas similitudes entre el estilo del Curioso Parlante y la labor de nuestros saineteros. Éstos, al modo de Mesonero, abusarán de los nombres significativos para exagerar hasta lo caricaturesco los rasgos que caracterizan al tipo: Si Mesonero llama a un viejo alegre «Don Plácido Cascabelillo", a un pícaro «Don Solícito Ganzúa», y a un perpetuo aspirante a «trepar» socialmente, «Don Teodoro Sobrepuja», etc., también nuestros sainetes están repletos de estos nombres que intentan retratar al tipo en cuestión»: “Don Guarrete», falso socialista hipócrita que sólo utiliza la política para aprovecharse de los demás (Los Descamisados, L. Silva-Arniches, 1893); «Don Judas», prestamista avaro que sólo piensa en el dinero ( $E l$ vil metal, J. Burgos, 1893); «Don Casto», sesentón que ha pasado la vida seduciendo a mujeres y teniendo muchísimos hijos (La Abuela, R. Vega, 1884); también aparece «Don Casto» en Los Baños del Manzanares (R. V. 1875) como marido mujeriego; «Doña Caridad Trompeta», vieja beata y tacaña ( $A$ la puerta de la Iglesia, R. Vega 1876); tres jóvenes estudiantes de derecho, música y alférez de artillería se llaman respectivamente «Justiniano», «Puntillo» y «Espoleta» (Pepa la Frescachona..., R. Vega 1886); “Don Cenón», será el eterno hambriento que siempre aspira a ser invitado (Merienda de negros, F. Manzano, 1887); «Homobono», tipo infeliz y bonachón (Boda y bautizo, V. Aza-M. Echegaray, 1895) etc.

Si en Mesonero ocurre «que los mismos caracteres reaparecen en cuadros diversos formando así un pequeño mundo de ficción.... ${ }^{53}$, entre los sainetes ocurre que los diversos autores repiten las mismas caricaturizaciones forjando así el tipo que actúa de la misma manera en los distintos sainetes.

Finalmente los conceptos de «tipo» y «escena» en Mesonero coincidirán paralelamente con los de los sainetes: todos los cuadros de Mesonero corresponderían a las escenas, en donde los tipos entran como componentes de las mismas, siendo raro que el autor los bosqueje sueltos, según afirma Montesinos. Los saineteros se inspirarán en ello para la estructura del sainete moderno en el que el cuadro-(s) es una sucesión de escenas constituidas a base de la presentación de tipos.

53 J.F. Montesinos, $O b$. cit. pp. 64 y ss. 


\section{INTENCIONALIDAD ETICA DEL SAINETE MODERNO}

El panorama que nos presenta el entremés áureo bajo pretexto de jocosidad: justicia apaleada, padres engañados, maridos burlados, ingenuos chasqueados, es consecuente con la actitud, que subyace en el entremés clásico, de una cierta insensibilidad ante la imperfección humana, insensibilidad más aparente que real pues estas burlas sobre el matrimonio, la justicia, la propiedad, etc., precisamente sólo «son eficaces en sociedades donde se las tiene por instituciones básicas" ${ }^{54}$.

El sainete fin de siglo carece absolutamente de dichos "vuelos de la fantasía" que servían a los entremesistas clásicos para reírse de las instituciones y convenciones sociales, por otra parte, sólidamente establecidas; frente al «desvio del entremés por la moraleja explícita o la ejemplaridad flagrante», frente a esa ruptura - aunque sea en bromade la norma, nuestro moderno entremés o sainete finisecular, propugna siempre lo contrario, la no transgresión de la moral convencional social, explicitando casi siempre su moraleja y su intencionalidad ética. Tanto en los sainetes en los que salen a relucir cuestiones sociales, como en los de asunto amoroso, la intención didáctica va siendo constatada a lo largo de la pieza, y en muchas ocasiones, en la famosa y tradicional despedida de los actores al público, es aclarada y repetida abiertamente.

El sainete moderno consolida pues el orden moral y social establecido, el cual no sufre ni se resquebraja nunca. El matrimonio, por ejemplo, en los sainetes de enredo amoroso, es institución defendida y considerada como la única forma moral, y por lo tanto viable, de encauzar el sentimiento amoroso, aunque a veces sí se permite ironizar sobre él, por ejemplo en el sainete de Miguel Echegaray y Vital Aza (1895) Boda y Bautizo, Pancha, una cubana que hace de madrina de la boda, afirma: «... El matrimonio es una gran institución. Cásate, niña mía, cásate. Es preciso sostener las instituciones. Así lo dicen todos los gobiernos y todos los partidos». (Escena III.) En el mismo graciosísimo sainete, «Homobono» es obligado por su mujer, «Circuncisión» a animar al novio, su futuro yerno, que está visiblemente preocupado y triste:

Homoвono.- Hijo mío: dentro de breves horas te habrás despedido para siempre de la vida de soltero, de esa vida llena de goces, de encantos, de placeres; dentro de breves horas habrás perdido esa hermosa libertad que envidian todos.

CiRCUNCISIÓN.-( (Pero hombre!)

HOMOBONO.-Todos los que ignoran las delicias del matrimonio... (esc. V)

${ }^{54}$ Eugenio Asensio, Ob. cit. p. 251. 
Pero esto es a lo más a que llegan las ironías. El sainete moderno juega a menudo con las «falsas apariencias» en cuanto a honestidad, fidelidad, o dudoso comportamiento de la mujer o del marido, pero nunca tardan mucho en disiparse las dudas y aclararse todo el malentendido, que fue introducido como un mero recurso dramático, creador del «suspense", dentro del enredo de la acción. Los ejemplos son múltiples: maridos momentáneamente descarriados de su matrimonio, vuelven al redil renegando de sus devaneos: De Verbena (J. de Burgos, 1885), El Ciclón (E.S. Pastor, 1891). Las aventuras o calaveradas de algún que otro personaje con alguna moza del pueblo o chula, a la que ha dejado embarazada, acaban siempre en matrimonio reparador de la falta: Providencias Judiciales R. de la Vega, 1875), Boda y Bautizo (V. Aza-M. Echegaray, 1895), exactamente igual si los novios son descubiertos juntos, aunque sea en casta conversación, son obligados por sus respectivos progenitores a matrimoniarse (a veces son ellos mismos los que provocan el incidente para acelerar la boda) como el El cura del Regimiento (E. Sánchez Pastor, 1895), El señor Luis el Tumbón o Despacho de huevos frescos ( $R$. de la Vega, 1897). Sin embargo, a pesar de este conformismo y acatamiento riguroso a las formas y a la moralidad de la época, conviene observar que en el moderno sainete se propugna una honestidad veraz, no una moral formalista. Esto es patente, por ejemplo, en el concepto de la honra femenina; ésta es un valor en sí, no sólo algo vertido al exterior como reputación social, sino con significación propia y sincera, como podemos comprobar en las palabras finales de La Revoltosa (J. López Silva-C. Fdnez. Shaw, 1897), cuando Felipe, una vez declarado su amor a Mari Pepa y ésta haberle correspondido, incómodo por tanta «revolución» que la coqueta Mari Pepa había producido en el vecindario masculino, le dice:

Y oye tú. Mañana mismo ya estás cogiendo las planchas y cambiando de vivienda, que esta atmósfera es malsana!

A lo que contesta Mari Pepa, con ese nuevo sentido de la «honra» ya galdosiano y totalmente contrario a la caricaturesca «honra» del teatro de Echegaray:

Mari PePa.-No tengas cuidado, Felipe. que la mujer que es honrada.

lo que es si quiere guardarse,

en todas partes se guarda.

SOLEDAD.-iArsa a la verbena! ¡Viva Felipe! 
Coro.- iVamos!

FELIPE.-iEn marcha!

$Y$ aqui da fin el sainete.

MARI PEPA.-Perdonad sus muchas faltas. (Música)»

CAE EL TELÓN

La opinión de Mari Pepa, la Revoltosa, expresa bien claramente que la cuestión de ser o no ser «honrada» una mujer estriba en su comportamiento real y auténtico y en sus sentimientos interiores, y no en absoluto en el ambiente exterior ni en las apariencias.

La concepción contraria del "honor», como reputación plasmada en la honra femenina vertida hacia el exterior, tan común en el teatro serio de la Restauración, está satirizada en multitud de ocasiones, entre las que se encuentra el sainete de C. Arniches y J. López Silva, El amo de la calle (C. Arniches-J. López Silva, 1910). Aquí las alusiones a la «honra" son pura parodia de lo que sucedía en el teatro de declamación serio postromántico: Paco, «el amo de la calle», intenta seducir a la casada Julia, la cual viendo sus intenciones se venga gastándole una pesada broma: Comienza por decirle, cuando se halla con él y su marido está llamando a la puerta, que Paco debe abrirle sin tener miedo, a lo que contesta Paco:

PaCo,- ¡No!... imiedo sí que no! Es por tu honra... ¡Por tu honra!

Julia (llorosa): -iSi, es verdá, no me acordaba!, ¡mi honra!, ¿qué has hecho de mi honra...?

La broma de Julia continúa hasta apresar a Paco dentro de un baúl y enviárselo a su mujer, Genoveva, que a su vez le está engañando con dos amantes. Genoveva, ante la irremediable presencia de su marido exclama, en plena comicidad de la situación:

¡Ay, qué disgusto!... ¡Mi honra! ¡Me voy con mi madre! ¡Mi honra!

Vemos pues los dos tipos de «honra» femenina que aparecen en los sainetes, la primera en La Revoltosa que es la que se defiende en ellos como norma moral que debe seguir la mujer honesta; la segunda "honra» en El amo de la calle sólo aparece en los sainetes como algo caduco, trasnochado e irreal propio tan sólo de los grandes dramones que sucedian en las tablas, y en consecuencia merecedor sólo de risa, no de consideración, y por lo tanto parodiado tal y como aparece en la escena transcrita. 
La moraleja o intención ética que explícitamente manifiesta el sainete a su término, no sólo atañe a la «honestidad» o fidelidad en instituciones como el matrimonio, sino a aspectos más generales de la moralidad pública, como el afán de vivir a costa del Estado sin trabajar, por ejemplo en Sanguijuelas del Estado (R. Vega, 1883):

Micaela.-... Ojalá los que hoy tiranizan y perturban al Gobierno por el maldito furor de ser empleados, ya que desatinan como UU., les imitarán a desengañarse.

ARISTIDES. - Y para que nunca falten

los versitos de ordenanza

aquí concluye el sainete.

En Restaurant de las tres clases (J. Burgos, 1889), la crítica va dirigida a los parásitos de todas las clases sociales, alta, media y baja:

\author{
Cuántas inauguraciones \\ he presenciado como ésta. \\ Prevención, juicio de faltas \\ y multas. ;Valiente idea \\ la del amo!: ;Restaurant \\ de las tres clases!... ¡Babjeca! \\ de tres clases diferentes \\ y una sola verdadera: \\ La clase de los perdidos \\ con frá, levita o chaqueta. \\ (Al público) Y ahora, si este pasillo \\ no ha disgustado \\ y tú me lo demuestras \\ con un aplauso, \\ te doy palabra \\ que no vuelvo a estos sitios \\ hasta mañana. (Telón al compás de una habanera.)
}

Otra moraleja explícita de los sainetes será el excesivo apego al dinero, por ejemplo en El vil metal (J. Burgos, 1893):

\footnotetext{
Fernando. - $Y$ no es mala

la lección que nos ha dado mi tío después de muerto, para que yo viera claro el efecto que en el mundo hace el dinero rodando ...jcuántas mudanzas y cambios! menos los sentimientos honrados.
} 
(Al público) Público y señor; tú que eres justo y desinteresado,

si el sainete te entretuvo,

prémianos con un aplauso.

Así pues, el sainete moderno propugna una ética de acuerdo con la moral social establecida; las críticas que sobre ella se ejercen son en orden al perfeccionamiento del sistema y a corregir las desviaciones debidas a la falta de honradez de algunos hombres o sectores de la sociedad, pero nunca a cuestionarse dicha sociedad.

La felicidad conseguida al final del sainete es consustancial al género: no hay final desdichado en ninguno de ellos. Creemos que la necesidad de autocontemplación de un pueblo feliz, por encima de sus miserias, que experimentaba el público, junto con la necesidad de diversión partiendo de la realidad - aunque idealizada - no de una evasión, son dos respuestas más al éxito del sainete finisecular, que podríamos añadir a los placeres señalados por Salaün del lenguaje y de la música (en el caso de los sainetes líricos), frutos todos ellos del pacto cultural propiciado por la convención social del sistema de la época ${ }^{55}$.

55 Serge Salaün, "El Género Chico, o los mecanismos de un pacto cultural", en El teatro en España a partir del siglo XVI. Anejos de la Revista «Segismundo", Madrid, C.S.I.C., 1963, pp. 251-261. 